\title{
Physical physiological and biochemical changes during pregnancy
}

\author{
Preeti Sharma $^{1, *}$, Anu Singh ${ }^{2}$, T K Mahopatra ${ }^{3}$, Pradeep Kumar ${ }^{4}$, Shailaza Shrestha ${ }^{5}$ \\ ${ }^{1}$ Associate Professor, ${ }^{2}$ Post Graduate Student, ${ }^{3,4}$ Professor, ${ }^{5}$ Tutor, ${ }^{1-4}$ Dept. of Biochemistry, Santosh Medical College and \\ Hospital, Ghaziabad, Uttar Pradesh, ${ }^{5}$ Dept. of Biochemistry, Heritage Institute of Medical Sciences, Uttar Pradesh, India.
}

*Corresponding Author:

Email: prcdri2003@yahoo.co.in

\begin{abstract}
Pregnancy is associated various physiological changes in order to ensure care, support and protection of the developing embryo and also prepare mother for labour and delivery. These changes influence all physical, physiological, biochemical and immunological status of the mother. Normal physiological changes that are observed include missed period, nausea, fatigue, motion sickness, mood swings, bloating, and tenderness in breast while biochemical and immunological changes include change in levels of blood levels of certain parameters like urea, creatinine, human chorionic gonadotropin, localisation of immune-modulators in uterus etc. This review highlights the important changes taking place during normal pregnancy so that it may aid in educating the expectant mothers regarding such changes facilitate them to cope up with proper health care.
\end{abstract}

Keywords: Pregnancy, Trimester, Foetus, Biochemical, Physiological, Physical, Immunity.

\section{Introduction}

Pregnancy refers to fertilization and developments of one or more offspring i.e. embryo or foetus, in uterus of woman. The expectant mother, during different trimesters, is accompanied by a series of physical, physiological and biochemical changes of which some are temporary and some persists for certain time span even after the termination of pregnancy while many others are permanent. The changes occurring affect all organs system of the woman's body. ${ }^{1}$ these changes observed from the time of conception are necessary to support and nourish the both the growing foetus and the mother. Broadly, physiological changes occurring during the pregnancy can be categorized as the local changes which refers to the changes affecting reproductive organ only and the systemic changes that affects the entire body. Significant changes in hormone levels can also be observed that alter the functions of heart, lungs, kidneys and gastrointestinal system. ${ }^{2}$ various signs and symptoms of pregnancy are elaborated in Table 1.

Table 1: Signs and symptoms of pregnancy

\begin{tabular}{|c|c|c|}
\hline S. No. & Signs and symptoms & Time period \\
\hline 1 & Mild cramping and spotting & week 1 to 4 \\
\hline 2 & Missed period & week 4 \\
\hline 3 & Fatigue & week 4 or 5 \\
\hline 4 & Nausea & week 4 to 6 \\
\hline 5 & Tingling or aching breasts & week 4 to 6 \\
\hline 6 & Frequent urination & week 4 to 6 \\
\hline 7 & Bloating & week 4 to 6 \\
\hline 8 & Motion sickness & week 5 to 6 \\
\hline 9 & Mood swings & week 6 \\
\hline 10 & Temperature changes & week 6 \\
\hline 11 & High blood pressure & week 8 \\
\hline 12 & Extreme fatigue and heart burn & week 9 \\
\hline 13 & Motion sickness & week 5 to 6 \\
\hline 14 & Faster heartbeats & week 8 to 10 \\
\hline 15 & Breast and nipple changes & week 11 \\
\hline 16 & Acne & week 11 \\
\hline 17 & Noticeable weight gain & week 11 \\
\hline 18 & Breast and nipple changes & week 11 \\
\hline 19 & Pregnancy glow & week 12 \\
\hline
\end{tabular}


Pregnancy also known as gestation period that usually lasts for 40 weeks, beginning from the first day of the women's last menstrual period. It is further divided into three trimesters namely first, second and third each with three months duration. Each trimester is associated with different physiological changes listed in Table 2.

Table 2: Normal physiological changes in all trimesters of pregnancy

\begin{tabular}{|l|c|c|}
\hline \multicolumn{1}{|c|}{ First trimester } & Second trimester & Third trimester \\
\hline Fatigue & Breast changes & Fatigue \\
\hline Breast tenderness & Leg cramps & Back pain \\
\hline Increased urination & Back pain & Pelvic ache and hip pain \\
\hline $\begin{array}{l}\text { Fullness or mild aching in lower } \\
\text { abdomen }\end{array}$ & Pelvic ache and hip pain & $\begin{array}{c}\text { Stretch marks and other skin } \\
\text { changes }\end{array}$ \\
\hline
\end{tabular}

\section{Changes Observed In Pregnancy Physical Changes}

Fatigue: It refers to sensation of tiredness or overtired, low energy level, drowsiness and sleepy state.

Headaches: Headaches are common and occur usually due to hormonal and postural changes. ${ }^{3}$ The other possible causes of headache during pregnancy are lack of sleep, stress, eyestrain etc. Sometimes, headache in pregnancy are indicative of pre-eclampsia. ${ }^{4}$ It can be manages by drinking plenty of water, taking complete sleep and seeking medical help if necessary.

Frequent urination: Frequent urge to void is also more often observed. In such cases, plenty of fluids are recommended to prevent dehydration.

Increased vaginal secretions: The vaginal secretions are thin and milky. For better hygiene small pads with cotton underwear should be worn in addition to having regular cleanliness of genitelia. In case of presence of itching sensation or frothy, smelly and colored discharge medical help must seeked.

Light headedness: It may occur due to over fasting therefore, regular meals in small quantity and regular interval of time is necessary.

Physiological Changes

Endocrine System/ Hormonal Changes

Pituitary hormones: In pregnancy pituitary gland enlarges due to hypertrophy of cells producing prolactin. ${ }^{5}$ The levels of LH and FSH drastically decline due to the increased levels of oestrogen and progesterone. ACTH, melanocyte stimulating hormone and prolactin levels also increase. Similarly growth hormone and oxytocin levels increase while ADH level are unchanged during pregnancy. ${ }^{1}$ However decrease in osmolality due to low sodium level causes resetting of osmo-receptors that facilitate anti-diuretic hormone (ADH) and thirst. ${ }^{6}$

Thyroid and parathyroid gland: There is increase in level of Thyroid binding globulin (TBG) due to high oestrogen levels, resulting in increased level of T4 and T3 over the first half of pregnancy. Serum concentrations of TSH are decreased in the first trimester. TSH production is stimulated after the first trimester. Increase in TSH is may indicate iodine deficiency or subclinical hypothyroidism which is mostly found in women with pregnancy. Therefore
WHO has recommended an increased intake of iodine during the time of pregnancy (around 100-200 $\mathrm{mg} /$ day). ${ }^{7}$ The iodine level should be maintained in pregnancy. so that there is production of adequate amount of thyroid hormones to fulfil the increased demand of pregnancy. The gland must be routinely investigated for the presence of goitre, as the size of gland enlarges by $25 \%$ in patients with iodine deficiency. Similarly the need for calcium is also high to ensure proper growth of foetus. The calcium needs doubles by $12^{\text {th }}$ weeks of gestation. Serum calcium levels in maternal circulation are maintained by parathyroid hormone and calcitonin via changes in intestinal absorption. ${ }^{8}$

Adrenal Gland: Adrenal gland produces mineralocorticoids, glucocorticoids and androgens. Stimulation of rennin angiotensin aldosterone (RAA) system causes 3 folds and 10 folds increase in aldosterone level in first and third trimester respectively. ${ }^{9}$ Levels of cortisol, corticosteroid binding globulin and adrenocorticotropic hormones also increase which can be manifested by signs like stria, increased blood pressure, facial plethora and impaired glucose tolerance. ${ }^{10}$ Cortisol favours lipogenesis and fat storage. Cortisol is also a hyperglycaemic hormone causing increase in blood sugar level. ${ }^{11}$

Cardiovascular System Changes: The cardiac output first increases by $20 \%$ till $8^{\text {th }}$ week of gestation, that further rises upto $40 \%$ and maximum increase is observed at $20-28^{\text {th }}$ week of gestation. There is further increase in cardiac output, stroke volume and heart rate. ${ }^{1}$ In the first two trimesters, blood pressure is lower than normal but it returns to normal in the third trimester. There is an increased risk of pulmonary oedema, if there is increased pulmonary capillary permeability secondary to pre-eclampsia. The cardiovascular changes are mediated by nitric oxide, estradiol and prostaglandins ${ }^{4}$

Respiratory System Changes: The respiratory changes observed are increased tidal volume (by $200 \mathrm{ml}$ ), increase in vital capacity and decrease in residual volume. In later stages of pregnancy, there may be decrease in tidal volume due to splinting of the diaphragm. There is a significant increase in oxygen demand during normal pregnancy due to increased 
metabolic rate. There is a state of compensated respiratory alkalosis preventing changes in $\mathrm{Ph} .{ }^{1}$ Lower maternal $\mathrm{pCO}_{2}$ facilitates oxygen/carbon dioxide transfer to/from the foetus. Many women complain of feeling short of breath in pregnancy without hypoxia or explanatory pathology. ${ }^{12}$

Alimentary System Changes: Nausea and vomiting are common in early pregnancy. Gums become spongy, friable and prone to bleeding. The gastrointestinal motility is reduced and the transit time is consequently longer. This also allows for the increased nutrient absorption. Constipation is also common in some cases. ${ }^{13}$ Growth of uterus displaces stomach slightly upward causing increased intra-gastric pressure and decreased oesophageal sphincter tone that predisposes nausea and vomiting. ${ }^{14}$

Urinary Tract Changes: Glomerular filtration rate (GFR) and renal blood flow increases by $50-60 \%$ during pregnancy with the increase level of blood volume and cardiac output. Increased GFR causes increased excretion and reduced blood levels of urea, creatinine, uric acid and bicarbonate. The smooth muscle in renal pelvis and ureter are relaxed and dilated. Also, the kidneys increase in size and ureters become longer, more curved and with an increase in residual urine volume. The risk of urinary tract infection increases as the smooth muscle of urinary bladder relaxes with increase in its capacity. Up to $30 \%$ pregnant women may develop acute pyelonephritis (kidney infection). ${ }^{15}$

Haematological Change: Effects of oestrogen and progesterone on kidneys results in increased plasma volume by around $45 \%$. These hormones stimulate rennin release thereby activating RAA system leading to retention of sodium and water. Increase in level of erythropoietin increases the total red cell mass by $20 \%$ till the end of the second trimesters but haemoglobin concentration does not show such drastic changes, since compared to plasma volume increase in red cell mass is comparatively small. ${ }^{16}$ This may be termed as physiological anaemia induced by pregnancy. The platelet count tends to fall during pregnancy. However, there is no change in mean corpuscular volume and mean corpuscular haemoglobin concentration. During pregnancy the serum iron level falls and total iron binding capacity increases. Clotting factors (like VIII, IX, X) and fibrinogen increase while fibrinolytic activity decreases thereby producing hyper-coagulable state. ${ }^{1}$

Metabolic Changes: The metabolic rate increases slowly over the course of pregnancy by $15-20 \%$. Though it is assumed that there is no significant increase in the requirement of energy during the first or second trimesters, it is increased by around $200 \mathrm{kcal}$ per day in the third trimester. Normal weight gain in pregnancy is 11.4 to $15.9 \mathrm{~kg}$ for a woman of normal body mass index (BMI) of which approximate $5 \mathrm{~kg}$ is the foetus, placenta, membranes and amniotic fluid and the rest mass is of maternal stores of fat and protein and increased intra-and extra-vascular volume. ${ }^{17}$

Pregnancy is considered diabetogenic state. There is hyperplasia of pancreatic $\beta$ cells causing high insulin level, increase in insulin sensitivity at early stage of pregnancy followed by insulin resistance in second and third trimester. These effects are mediated by diabetogenic hormones like placental lactogen, prolactin, growth hormone, cortisol and progesterone. They interfere with insulin signalling and induce insulin resistance. However fasting glucose remains low due to:

1. Increased glycogen storage

2. Decreased hepatic glucose formation

3. Increased use by foetus. ${ }^{18}$

Serum lipids like cholesterol, low density lipoprotein (LDL), high density lipoprotein (HDL) and triglycerides are increased. LDL is important for placental steroidogenesis. Amino acids are also actively taken up by growing foetus. Protein catabolism decreases as stored fat are used as energy source. ${ }^{18}$

Table 3: Key physiological changes in pregnancy

\begin{tabular}{|l|l|l|}
\hline S. No. & \multicolumn{1}{|c|}{ Systems } & \multicolumn{1}{c|}{ Changes } \\
\hline 1 & Hematological system & $\begin{array}{l}\uparrow \text { Blood cells, } \uparrow \text { Clotting factor, } \uparrow \text { Fibrinolytic activity, Iron } \\
\text { deficiency and anemia }\end{array}$ \\
\hline 2 & Cardiovascular system & Tachycardia, $\uparrow$ Cardiac output, $\uparrow$ Heart rate, $\uparrow$ Stroke volume \\
\hline 3 & Respiratory system & $\begin{array}{l}\text { Superior displacement of diaphragm, } \uparrow \text { Functional reserve } \\
\text { capacity, } \uparrow \text { Risk of apnea and dyspnea, hyper-ventilation }\end{array}$ \\
\hline 4 & Gastrointestinal system & Nausea, Vomiting, Heat burn and acidity \\
\hline 5 & General & Mode and behavioral changes, increased nutritional demands \\
\hline
\end{tabular}

\section{Immune System}

There is alteration immune function during pregnancy in order to protect both mother and foetus from infections or immunological attack. Some factors associated with adoptive immunity such as $\mathrm{T}$ and $\mathrm{B}$ lymphocytes, production of $\mathrm{TH} 1$ and $\mathrm{TH} 2$ cytokines from naïve CD4 $\mathrm{T}$ cells etc. are reduced while some specific aspects of innate immune system like natural killer (NK) cell dendritic cell and monocytes are exacerbated. ${ }^{19}$ During pregnancy the variant of NK cell, also called uterine NK (uNK) cells concentrate in uterus and are implicated to have important role in implantation, remodelling of spiral arteries and trophoblast invasion. Type 2 cytokines (IL-4, IL-5, IL- 
10, IL-13) produced by uNK cells have protective role for foetus. ${ }^{20}$ Dysregulation in immunological mechanisms can result in complications of pregnancy like pre-term birth or miscarriage. ${ }^{21}$

\section{Biochemical Changes in Pregnancy}

Reduction in serum sodium: Increase in water and sodium retention and increase in plasma volume results in reduction of serum sodium by $3-5 \mathrm{mmol} / \mathrm{l} .^{22}$

Reduction in serum creatinine and urea: The glomerular filtration rate increases by up to $50 \%$ due to the increase in renal blood flow. ${ }^{14}$ Therefore, compared to the non-pregnant women, there is increased clearance of urea and creatinine in pregnant women resulting in lower serum concentration of these analytes. ${ }^{22}$

Reduced serum osmolality: During pregnancy, serum osmolality decreases due to increase in blood volume. It may reach its lowest level during the 10 week of gestation. ${ }^{23,24}$

Changes in glucose tolerance: In pregnancy there is a change in glucose tolerance during the different trimesters. The glucose tolerance in pregnancy is directly proportional to the glucose load or intake of glucose. In early pregnancy, glucose tolerance is normal and the secretion of insulin is based on the glucose load. ${ }^{25}$

Changes to fasting blood glucose: Generally, the fasting blood glucose level falls by $10-20 \%$ during the early stages of pregnancy. ${ }^{23}$ The hepatic glucose production increases during the first, second and third trimester of pregnancy which helps to meet the energy need of growing foetus.

Table 4: Biochemical changes in pregnancy ${ }^{26}$

\begin{tabular}{|c|c|c|}
\hline Parameters & In normal Pregnancy & Normal values (pregnancy) \\
\hline Hemoglobin & Decreased & $10.5-13 \mathrm{~g} / \mathrm{dL}$ \\
\hline WCC(White cell count) & Increased & $8-18 \times 109 / \mathrm{L}$ \\
\hline Sodium & Slightly decreased & $132-140 \mathrm{mmol} / 1$ \\
\hline Potassium & Slightly decreased & $3.2-4.6 \mathrm{mmol} / \mathrm{l}$ \\
\hline Urea & Decreased & $1.0-3.8 \mathrm{mmol} / \mathrm{l}$ \\
\hline Creatinine & Decreased & $40-80 \mathrm{mu} \mathrm{mol} / \mathrm{l}$ \\
\hline Fasting glucose & Unchanged & $3.0-5.0 \mathrm{mmol} / \mathrm{l}$ \\
\hline Serum Calcium & Decreased & $2.0-2.4 \mathrm{mmol} / \mathrm{l}$ \\
\hline Magnesium & Unchanged & $0.6-0.8 \mathrm{mmol} / \mathrm{l}$ \\
\hline Albumin & Decreased & $24-31 \mathrm{~g} / 1$ \\
\hline Bilirubin & Decreased & $3-14 \mathrm{mu} \mathrm{mol} / \mathrm{l}$ \\
\hline ALT & $\begin{array}{c}\text { Unchanged or slightly } \\
\text { decreased }\end{array}$ & $1-30 \mathrm{u} / \mathrm{l}$ \\
\hline AST & $\begin{array}{c}\text { Unchanged or slightly } \\
\text { decreased }\end{array}$ & $1-21 \mathrm{u} / \mathrm{l}$ \\
\hline ALP & Increased & $125-250 \mathrm{u} / 1$ \\
\hline $\begin{array}{l}\text { TSH } \\
\text { (Thyroid stimulating hormone) }\end{array}$ & $\begin{array}{l}\text { Slightly decrease in the first } \\
\text { trimester, normal in the } \\
\text { second trimester slightly raise } \\
\text { in third trimester }\end{array}$ & $0.1-4.0 \mathrm{iu} / \mathrm{l}$ \\
\hline $\mathrm{FT}_{4}$ & Unchanged & $10-20 \mathrm{pmol} / \mathrm{l}$ \\
\hline $\mathrm{FT}_{3}$ & Unchanged & $3.5-6 \mathrm{pmol} / 1$ \\
\hline
\end{tabular}

\section{Conclusion}

Pregnancy is a state accompanied by various physiological, biochemical and physical changes in all three trimesters. We must be aware of various changes occur during normal pregnancy so that necessary timely precautions or measures may take in case if there is any deviation from the normal changes in order to prevent the loss of pregnancy.

\section{References}

1. Pillay S, Piercy CN, Tolppanen H, Mebazaa A. Physiological changes in pregnancy. Cardiovasc J Afr. 2016;27:89-94.

2. Davis MP, Walsh D. Mechanism of faigue. J Support Oncol .2010;8:164-74.
3. Menon R, Bushnell CD. Headache and pregnancy. Neurologists. 2008;14:108-19.

4. Sibai B, Dekker G, Kupferminc M. Pre-eclampsia. Lancet. 2005;365:785-99.

5. Prager D, Braunstein G. Pituitary disorders during pregnancy. Endocrinol Metab Clin North Am.1995;24:114.

6. Linheimer MD, Barron WM, Davison JM. Osmotic and volume control of vasopressin release in pregnancy. Am J Kidney Dis. 1991;17:105-11.

7. Monahan M, Boelaert K, Jolly K, Chan S, Barton P, Roberts TE. Costs and benefits of iodine supplementation for pregnant women in a mildly to moderately iodinedeficient population: a modeling analysis. Lancet Diabetes Endocrinol. 2015;3:715-22. 
8. Rasmussen PE, Nielsen FR. Hydronephrosis during pregnancy: a literature survey. Eur J Obstet Gynecol Reprod Biol. 1988;27:249-59.

9. Elsheikh A, Creatsas G, Mastorakos G Milingos $\mathrm{S}$, Loutradis D, Michalas S. The renin-aldosterone system during normal and hypertensive pregnancy. Arch Gynecol Obstet. 2001;264:182-85.

10. Yorke E, Atiase Y, Akpalu J, Kantanka OS. Screening for Cushing Syndrome at the Primary Care Level: What Every General Practitioner Must Know. Int J Endocrinol. 2017;2017:1-7.

11. Hughes RC, Rowan J, Florkowski CM. Is there a role for HbA1c in pregnancy? Curr Diab Rep. 2016;16:5.

12. Castro LC, Hobel CJ, Gornbein J. Plasma levels of atrial natriuretic peptide in normal and hypertensive pregnancies: a meta-analysis. Am J Obstet Gynecol. 1994;171:1642-51.

13. Niebyl JR, Goodwin JM. Overview of nausea and vomiting of pregnancy with an emphasis on vitamins and ginger. Am J Obstet Gynecol. 2002;186:253-55.

14. Koch KL. Gastrointestinal factors in nausea and vomiting of pregnancy. Am J Obstet Gynecol. 2002;186:S198-203.

15. Smaill FM, Vazquez JC. Antibiotics for asymptomatic bacteriuria in pregnancy. Cochrane Database Syst Rev. 2015;7:CD000490.

16. Whittaker PG, Macphail S, Lind T. Serial hematologic changes and pregnancy outcome. Obstet Gynecol. 1996;88:33-39.

17. Tanentsapf I, Heitmann BL, Adegboye AR. Systematic review of clinical trials on dietary interventions to prevent excessive weight gain during pregnancy among normal weight, overweight and obese women. BMC Pregnancy Childbirth. 2011;11:2-12.
18. Brizzi P, Tonolo G, Esposito F, Puddu L, Dessole $\mathrm{S}$, Maioli M, et al. Lipoprotein metabolism during normal pregnancy. Am J Obstet Gynecol. 1999;181:430-34.

19. Das PM, Bonney E, Caron K, Dey S, Erlebacher A, Fazleabas A, et al. Immune mechanisms at the maternalfetal interface: Perspectives and challenges. Nat Immunol. 2015;16:328-34.

20. Shrestha S, Sharma P, Kumar P, Saxena SP, Sharma R. Natural Killer Cells: An Insight into its Role in Pregnancy. J Clin Diag Res. 2018;12:1-7.

21. Gars ML, Kay AW, Bayless NL, Aziz N, Dekker CL, Swan GE, et al. Increased pro-inflammatory responses of monocytes and plasmacytoid dendritic cells to influenza A virus infection during pregnancy. J Infect Dis. 2016;214:1666-71.

22. Patricia OO, Christiana BA, OJ Raphael. Evaluation of changes in renal functions of pregnant women attending antenatal clinic in Vom Plateau State, North-Central Nigeria. Arch Appl Sci Res. 2013;5:111-16.

23. Brown MA, Whitworth JA. The kidney in hypertensive pregnancies-victim and villain. Am J Kidney Dis. 1992;20:427-42.

24. Schrier RW. Pathogenesis of sodium and water retention in high-output and low-output cardiac failure, nephritic syndrome, cirrhosis, and pregnancy. $N \mathrm{Med}$. 1988;319:1065-72.

25. Butte NF. Carbohydrates and lipid metabolism in pregnancy: normal compared with gestational diabetes mellitus. Am J Clin Nutr. 2000;71:1256-261.

26. Gaw A, Cowan RA, O Reilly DSTJ, Stewart MJ, Shepherd J. Specialized investigations: Pregnancy. Robert Britton. Clinical biochemistry - an illustrated colour text, 2nd edition. Edinburgh: Churchill Livingstone. 1999;140-43 